\title{
INFLUENCE OF LOW-CONDUCTIVE COATING ON INSULATION SYSTEM OF ROTARY ELECTRIC MACHINE
}

\author{
Petr Mráz ${ }^{*}$ — Vladimír Kindl ${ }^{* *}-$ Karel Hruška ${ }^{* *}$
}

\begin{abstract}
The discharge activity is well-known phenomenon in large rotating machines. Unfortunately it is not completely understood and explained phenomenon yet. Especially creeping (also called gliding) discharge activity in winding heads is not deeply investigated and interpreted/explained. All of mentioned discharges may be marked as partial discharges (PD) in general. This study offers two points of view on this problem. At the first place it is a finite element modelling (FEM) of two different slot arrangements used for analysis of the electrostatic field. Second, the measurement on real model of stator winding helps confirming the validity of modelled results.
\end{abstract}

K e y w or ds: partial discharge, measurement, modelling, finite element method

\section{INTRODUCTION}

The semiconducting coating is placed on the surface of high voltage stator bars and coils to prevent partial discharge [1-3]. Without presence of bar's semiconducting coating, PD would occur in small gaps between bars and slot sides. To protect this part of stator coil semiconducting coating is usually used (Fig. 1). Its resistivity is then in range of $0.1-10$ kilo ohms per area [4-6]. Out of the stator core PDs also occur but the cause is different. If the stator bar outgoing from the slot is coating-less, its insulation will be longitudinally stressed by non-linear electric field intensity of high gradient. To prevent this, the coating of higher resistivity (hundreds of kilo ohms per area) is used in case of slot region protection. In addition the coating is divided into several sections with stepped value of both the permittivity and the sheet resistivity [7-9]. Such a kind of surface treatment makes the curve of voltage stress more linear. Due to this modification the coil is much more resistant to PD. The theory is relatively well known, but the methodology of finite element modelling of such a phenomenon is not. So far there is no methodology to compute the voltage distribution over the length of the stator bar outside the slot.

\section{FINITE ELEMENT CALCULATION}

For solution of this problem a harmonic electric [10] analysis is supposed to be very suitable for determination of effects of alternating voltage in rotating machine insulating system. In this kind of analysis the electric field is derived [11] from the electric scalar potential. Capacitive effects and displacement current are taken into account. Neglecting the time-derivative of magnetic flux density, the system of Maxwell's equations reduces to

$$
\begin{aligned}
\nabla \times \vec{H} & =\vec{J}+\frac{\partial \vec{D}}{\partial t}, \\
\nabla \times \vec{E} & =0, \\
\nabla \cdot \vec{B} & =0, \\
\nabla \cdot \vec{D} & =\rho .
\end{aligned}
$$

As follows from equation (2), the electric field $\boldsymbol{E}$ is non-rotational, and may be derived from

$$
\vec{E}=-\nabla V
$$

where $V$ is electric (scalar) potential.

This gives

$$
\begin{aligned}
& \vec{J}=\left[\begin{array}{ccc}
\rho_{x} & 0 & 0 \\
0 & \rho_{y} & 0 \\
0 & 0 & \rho_{z}
\end{array}\right] \vec{E} \\
& \vec{D}=\left[\begin{array}{ccc}
\varepsilon_{x} & 0 & 0 \\
0 & \varepsilon_{y} & 0 \\
0 & 0 & \varepsilon_{z}
\end{array}\right] \vec{E}
\end{aligned}
$$

\subsection{FEM model design}

The mesh of the model (see Fig. 2) was optimized in the coating region in terms of maximal accuracy. With regard to the computation requirements some simplification had to be done. First only a small cut out of whole slot is modelled. Therefore the modelled winding has no winding heads. Furthermore the magnetic circuit can not be considered as laminated. The coating itself is modelled as a very tight volume of properties listed in Table 1.

University of West Bohemia, Pilsen, Czech Republic, ${ }^{*}$ Department of Technologies and Measurement, pmraz@ket.zcu.cz ${ }^{* *}$ Department of Electromechanics and Power Electronics, Univerzitní 2630614 Plzeň, vkindl@kev.zcu.cz,, khruska@kev.zcu.cz 
Table 1. Material properties considered in each model

\begin{tabular}{ccccccc}
\hline \multirow{2}{*}{ Region } & \multicolumn{3}{c}{ Resistivity $(\Omega /$ Area $)$} & \multicolumn{3}{c}{ Relative Permittivity $(-)$} \\
\cline { 2 - 7 } & \multicolumn{1}{c}{ Model l } & Model 2 & Model 3 & Model 1 & Model 2 & Model 3 \\
\hline Iron & $\mathrm{N} / \mathrm{C}$ & $\mathrm{N} / \mathrm{C}$ & $\mathrm{N} / \mathrm{C}$ & $\mathrm{N} / \mathrm{C}$ & $\mathrm{N} / \mathrm{C}$ & $\mathrm{N} / \mathrm{C}$ \\
Copper & $\mathrm{N} / \mathrm{C}$ & $\mathrm{N} / \mathrm{C}$ & $\mathrm{N} / \mathrm{C}$ & $\mathrm{N} / \mathrm{C}$ & $\mathrm{N} / \mathrm{C}$ & $\mathrm{N} / \mathrm{C}$ \\
Slot Wedge & $\mathrm{N} / \mathrm{C}$ & $\mathrm{N} / \mathrm{C}$ & $\mathrm{N} / \mathrm{C}$ & 5 & 5 & 5 \\
Air & $\mathrm{N} / \mathrm{C}$ & $\mathrm{N} / \mathrm{C}$ & $\mathrm{N} / \mathrm{C}$ & 1 & 1 & 1 \\
Coil Insulation & $\mathrm{N} / \mathrm{C}$ & $\mathrm{N} / \mathrm{C}$ & $\mathrm{N} / \mathrm{C}$ & 5 & 5 & 5 \\
Coating 1 & $\mathrm{N} / \mathrm{C}$ & $1 \mathrm{e}^{4}$ & $1 \mathrm{e}^{4}$ & 5 & 3 & 3 \\
Coating 2 & $\mathrm{N} / \mathrm{C}$ & $1 \mathrm{e}^{5}$ & $1 \mathrm{e}^{4}$ & 5 & 3.5 & 3 \\
Coating 3 & $\mathrm{N} / \mathrm{C}$ & $5 \mathrm{e}^{5}$ & $1 \mathrm{e}^{5}$ & 5 & 3.5 & 3.5 \\
Coating 4 & $\mathrm{N} / \mathrm{C}$ & $1 \mathrm{e}^{6}$ & $1 \mathrm{e}^{5}$ & 5 & 3.5 & 3.5 \\
\hline
\end{tabular}

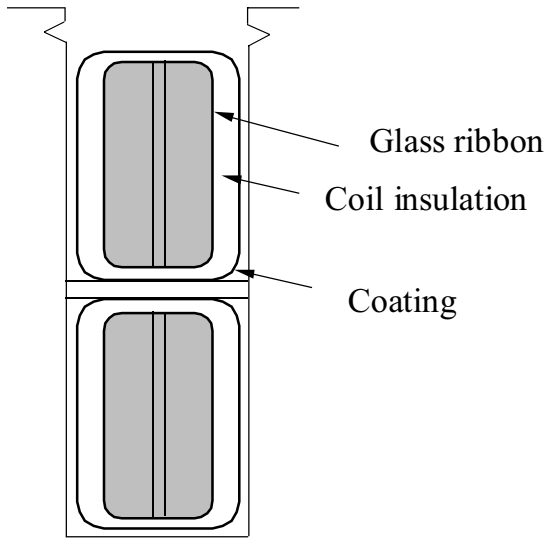

Fig. 1. Cross-Section of Stator Slot

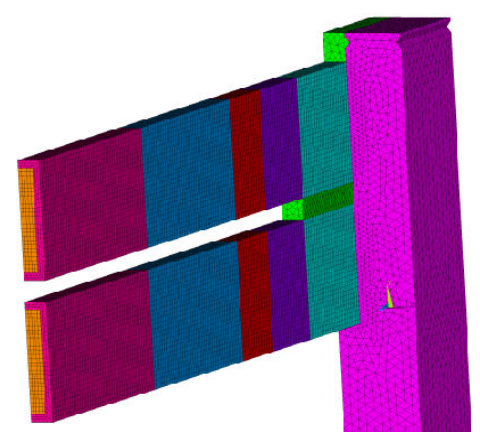

Fig. 2. Meshed Numerical Model

In our computations, three different models have been used. The first one was coating-less and serves for calculation of voltage distribution along the stator bar length without any improvements. The resulting curve is strongly nonlinear with high gradient. The second one included the coating and the resulting curve is therefore more linear. The third one is the combination of previous models. Its coating consists of two-stage semiconducting layer. Material properties of models are listed in Table 1, properties marked as N/C were not considered. Boundary conditions are set with regard to the real experiment. The magnetic circuit potential is grounded and the sta- tor bar is supplied by high voltage of $8 \mathrm{kV}$ (RMS) with frequency of $50 \mathrm{~Hz}$.

\subsection{FEM model results}

From computation the distribution of electric field intensity in each element of model's mesh is obtained. For better interpretation it is possible to map results into defined path over meshes elements. In this particular case we are interested mainly in surface of coating, hence two paths is defined as shown in Fig. 4.

\section{EXPERIMENTAL RESULTS}

The partial discharge (PD) testing was performed using a commonly available test system Doble-Lemke PD SMART, which allowed the measurement of the recommended IEC-magnitudes including the description of the PD behaviour in a well known PRPD-pattern. Sensitivity of the test circuit was from 4 to $40 \mathrm{pC}$, depending on used PD gain.

The measurement was accomplished according to measuring circuit shown in Fig. 5. Measuring circuit corresponds to IEC 60270 standard. [12] During this kind of measurement it is very necessary to consider so called self extinguish phenomenon. [13] This phenomenon occurs especially in case of large rotating machines. In fact it is a matter of the space charge and equalization of the charge in the initial stage during the PD measurement. In Fig. $6 Q(t) U(t)$ diagram is shown with good visible selfextinguish phenomenon. It is necessary to wait at least 10 minutes to stabilize the PD behaviour.

The measuring procedure itself consists of two main stages. In the first stage the inception voltage extinguish voltage $U_{e}$ is measured. After reaching inception voltage the voltage is increased to 1.2 times greater value. Then the voltage is decreased to extinguish voltage $U_{e}$ and then to 0.8 fold of $U_{e}$. This stage repeats five times.

In second stage of the experiment the time dependence of PD activity is measured. The measurement takes 10 minutes at $8 \mathrm{kV}$ voltage and apparent charge $Q_{i e c}$ and discharge current $I$ are measured. 


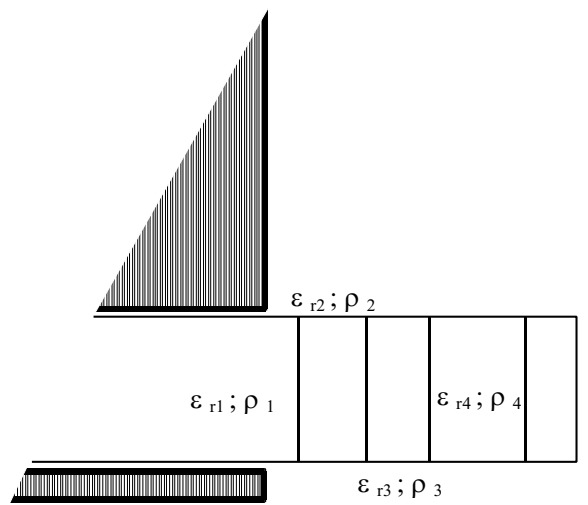

Fig. 3. Physical Properties of Modelled Regions

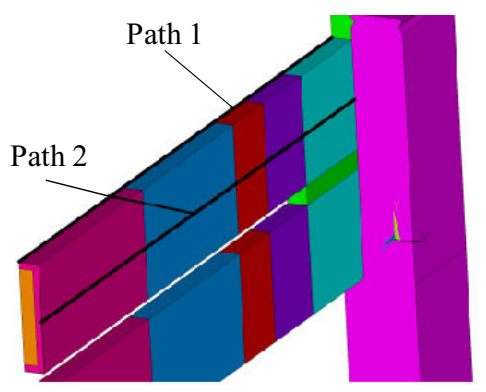

Fig. 4. Paths for Reading Results

Table 2. Measured PD data results

\begin{tabular}{lcccc}
\hline & $U_{\mathrm{i}}(\mathrm{kV})$ & $U_{\mathrm{e}}(\mathrm{kV})$ & $Q_{\text {iec }}(\mathrm{nC})$ & $I[\mu \mathrm{A})$ \\
\hline Bar 1 & 2.5 & 2.3 & 8.87 & 30 \\
Bar 2 & 4.3 & 4.1 & 1.71 & 4.2 \\
Bar 3 & 4.6 & 4.4 & 1.46 & 3.07 \\
\hline
\end{tabular}

The measurement was performed on laboratory model of large rotary machine stator. Three types of bars were measured. First bar was not wedged and had no anticorona protection. Bar number two was wedged and had two-phase anti-corona protection and finally bar number three was wedged as well, but it had four-phase anticorona protection.

Partial discharge testing belongs to one of high applicable insulating material test methods within electri- cal machines. This non-destructive test method allows determination of PD activity in measured subject. [1416] The characteristic parameters according to IEC 60270 standard as inception voltage $U_{i}$, extinguish voltage $U_{e}$, apparent charge level $Q_{i e c}$ and average discharge current $I$ (in $\mu \mathrm{A}$ ) were measured and analyzed. Furthermore two types of PD diagrams were used to define which types of partial discharges were occurred. First diagram is well-known and used PRPD (Phase Resolved Partial Discharge) diagram. [17-22] In fact, it is $\Phi-q-n$ diagram which shows dependence of apparent charge to phase of the testing voltage with repetition rate parameter. Output from this diagram is typical pattern which allows recognizing the partial discharge type. Of course, it is necessary to use some database of typical PRPD patterns. Next used diagram was Cumulative charge diagram which helps together with PRPD diagram to specify the recognition of the PD type.

In this measurement three kinds of PDs, depending on the bars properties, occur [22-24]. In case of first bar slot discharges, internal partial discharges and gliding discharges occurred. In case of bars number two and three the slot discharges were suppressed, since these bars were wedged. Furthermore internal PDs have been detected since they depend on insulation processing and they were more or less similar to previous case (resin-rich technology was used for these bars). Also gliding discharges, depending on anti-corona protection, occurred.

Bar number one shows obviously all three types of partial discharges. Level of apparent charge is $8.87 \mathrm{nC}$ (see Table 2) and inception voltage is very low in comparison to bars number two and three. The cumulative charge diagram (Fig. 7) and PRPD pattern (Fig. 8) show that main occurring PDs may be identified as slot and gliding discharges. See Fig. 7 and phase gradient in positive $\left(0^{\circ}--180^{\circ}\right)$ and negative $\left(180^{\circ}-360^{\circ}\right)$ half sine wave of testing voltage. Unsymmetrical distribution of cumulative charge according to the phase of testing voltage is typical for slot and mainly gliding discharges.

In case of bar number two the gliding and slot discharges were suppressed. The bar was wedged and anticorona protection was used. The apparent charge is in this case lower - $1.71 \mathrm{nC}$ and inception voltage of PDs is higher than in case of bar number one. Also the PRPD

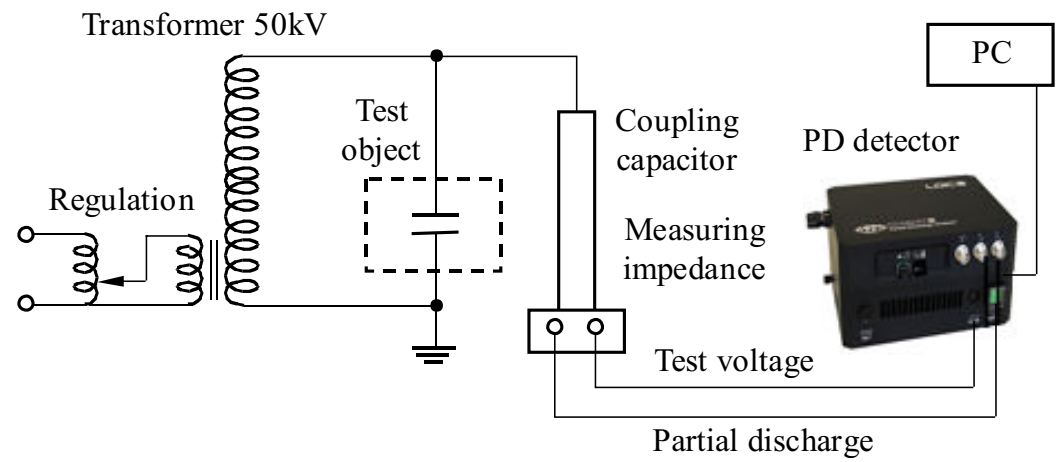

Fig. 5. PD Measurement Test Circuit 


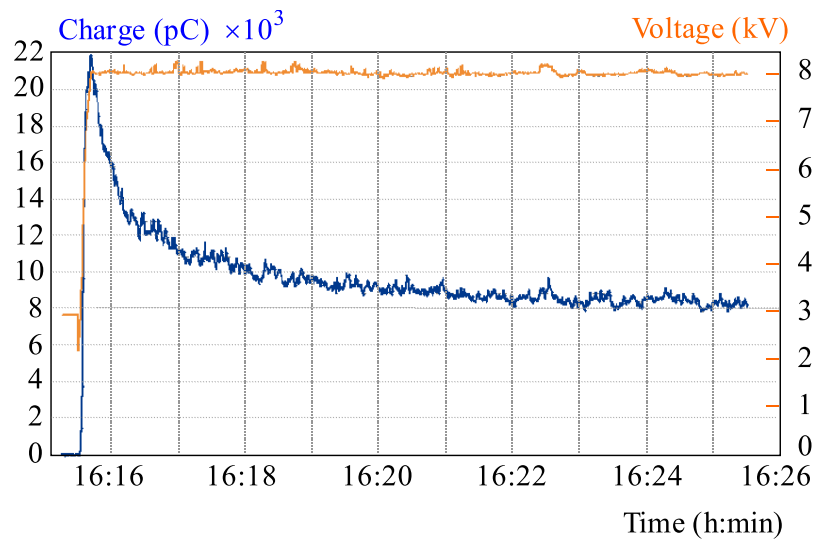

Fig. 6. $Q(t) U(t)$ Diagram for Bar Number One - Observation of Self-Extinguish Phenomenon

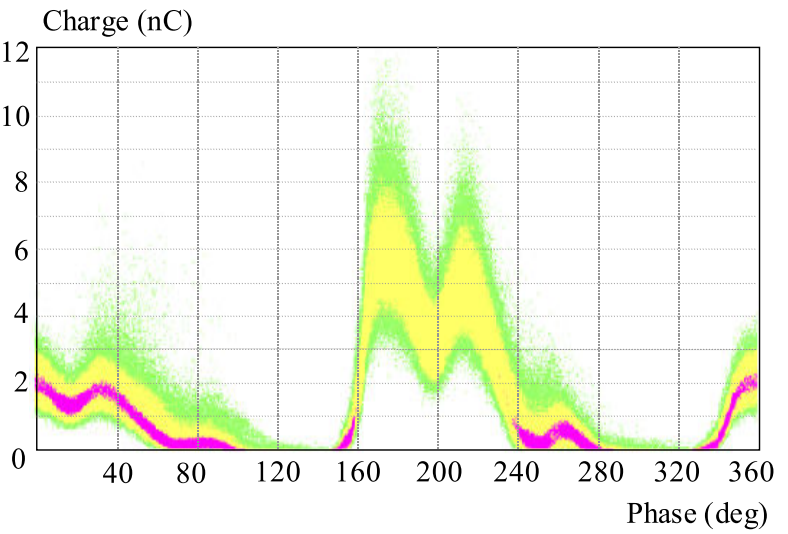

Fig. 8. PRPD Diagram for Bar Numer One

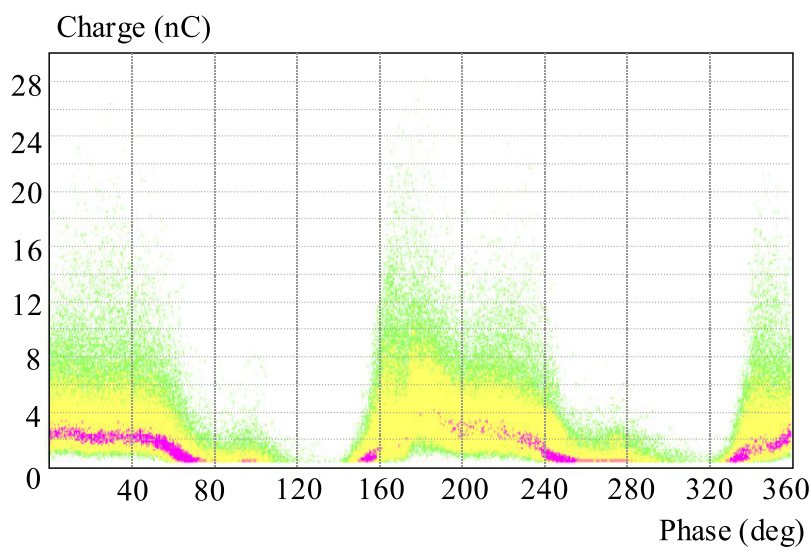

Fig. 10. PRPD Diagram for Bar Number Two

pattern (Fig. 10) shows symmetrical shapes in both halfwaves of testing sine wave. As mentioned before, the slot and gliding discharges occur, but in limited size. In cumulative charge diagram the phase gradient of apparent charge is more or less symmetric in negative and positive half sinus wave, but still there is it is possible to observe higher absolute size of apparent charge. It means that gliding discharges still occur.

Finally bar number three proves that four-phase anticorona protection decreases the gliding discharge occur-

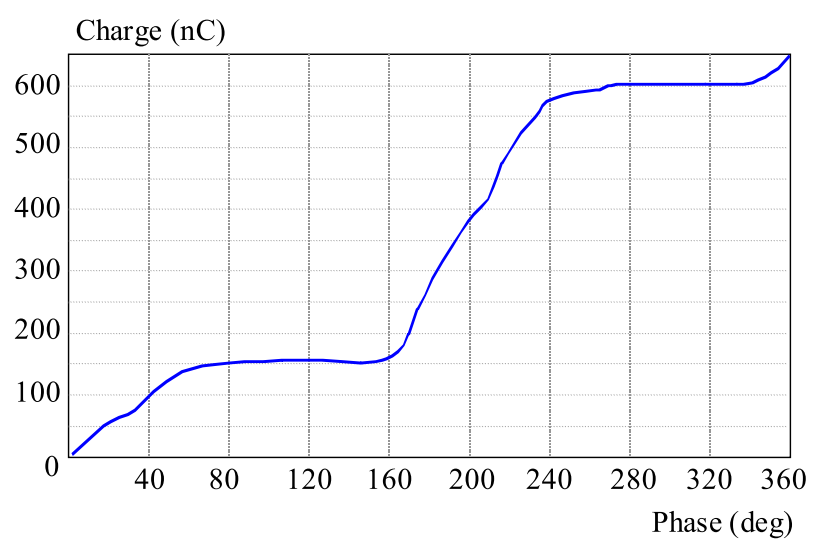

Fig. 7. Cumulative Charge Diagram for Bar Numer One

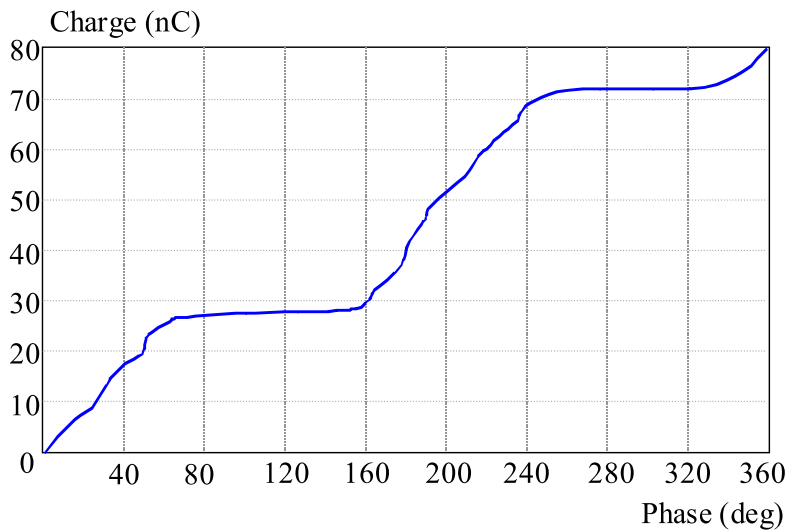

Fig. 9. Cumulative Charge Diagram for Bar Numer Two

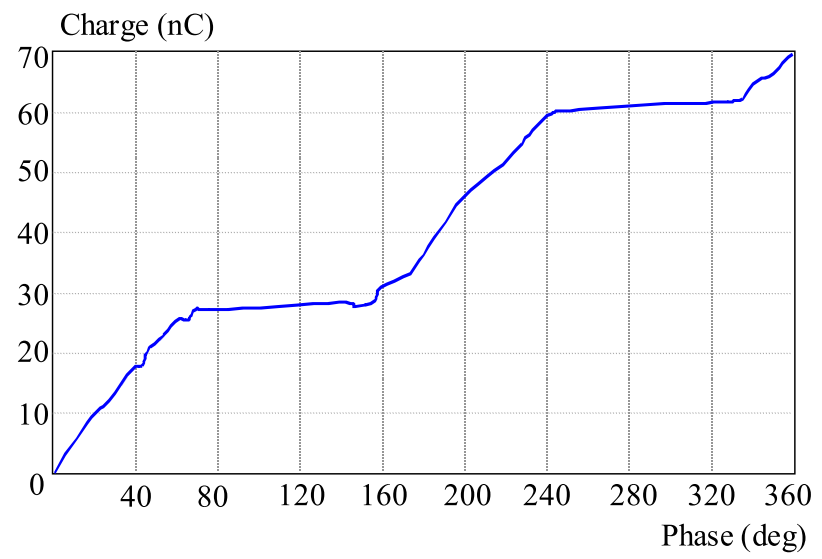

Fig. 11. Cumulative Charge Diagram for Bar Number Three

rence. Apparent charge was reduced to $1.46 \mathrm{nC}$ and inception voltage increased to $4.6 \mathrm{kV}$. Also the PRPD diagram has typical shape for internal PD activity with slightly superposed gliding and slot discharges. This theory is supported by Cumulative charge diagram which clearly shows that gradient of apparent charge is more or less the same and the absolute magnitude as well. It means that gliding discharge activity was suppressed. 


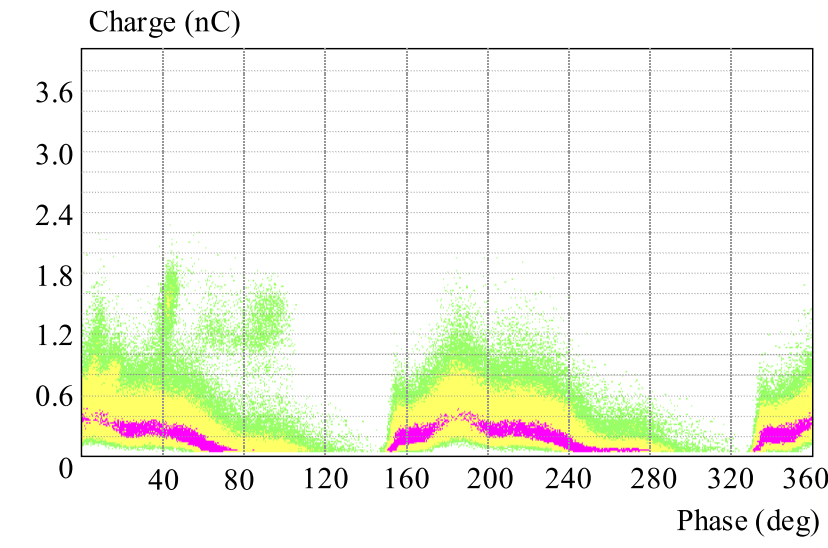

Fig. 12. RPD Diagram for Bar Number Three

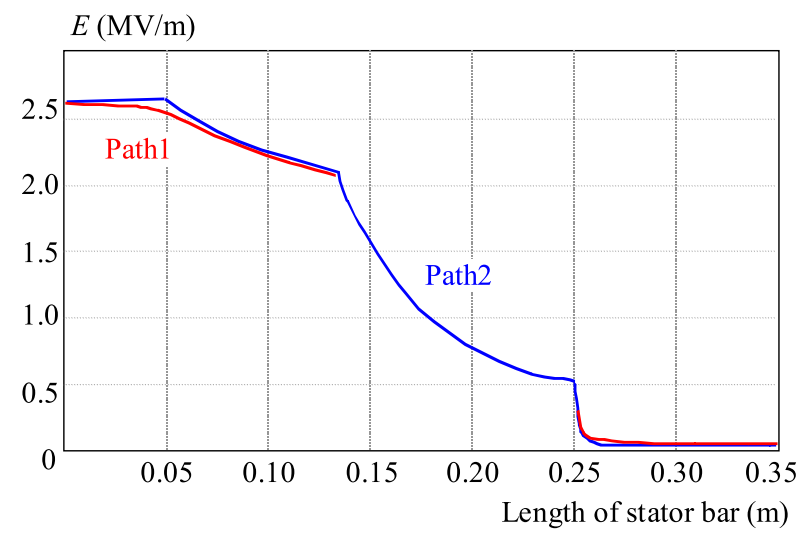

Fig. 14. Electric Field Intensity Along Wedged Bar With TwoPhase Anti-Corona Protection

\section{DISCUSSION}

As seen from previous section, the mechanism and appearance of partial discharge is different for different physical layouts of stator winding insulations and its semiconductong coating. The mechanism of creations of the partial discharge for each possibility may be observed using prepared FEM models. As mentioned, three layouts of winding insulations with semiconducting coating have been measured and modelled.

First modelled possibility considers a bar with basic insulation laid in stator slot without any slot wedge and semiconducting coating (see Fig. 13). In this case the results from the model show a high electric field intensity drop, therefore a high gradient of electric field. In a real machine this causes a high partial discharge activity caused mostly by gliding and slot discharges, which agrees with results of measurement.

Second possibility was a wedged bar with two-phase anti-corona semiconductor protection slot insulation. In this case the real measurement shows elimination of slot discharges and reduction of gliding discharges. As seen from results of the numeric model (see Fig. 14), this effect has been achieved by three step electric field intensity drop, which eliminates strong gradient observed in previous case.

Last modelled possibility shows a wedged bar with four phase anticorona protection. The measurement in this

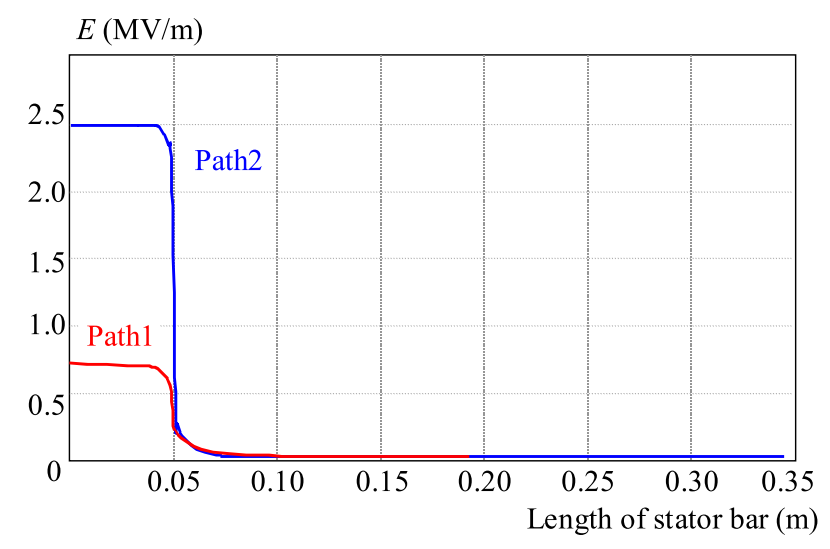

Fig. 13. Electric Field Intensity Along Non-Wedged Bar Without Semiconducting Coating

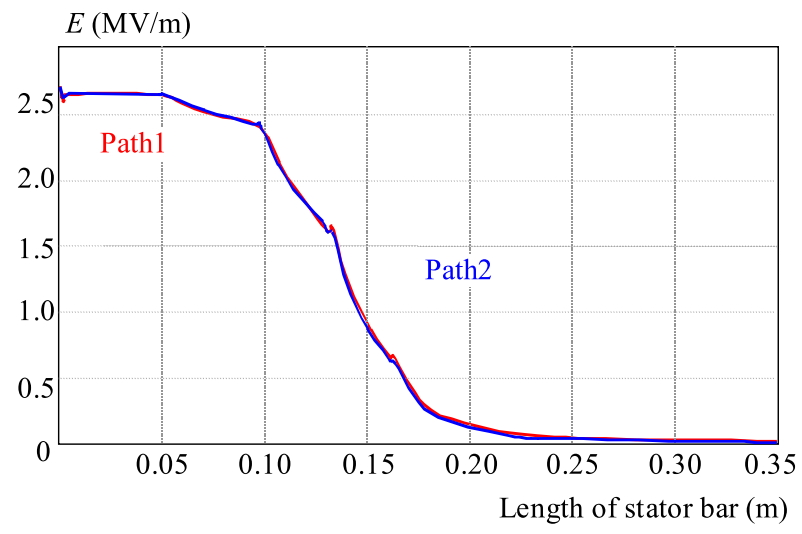

Fig. 15. Electric Field Intensity Along Wedged Bar With FourPhase Anti-Corona Protection

case shows lowering of gliding discharges and increase of inception voltage while inner partial discharges remain at the same niveau as in previous cases. This corresponds with FEM results (Fig. 15) which show lowest gradient of electric field at the end of stator packet and best coherence of final electric field space dependence.

This layout is very important from the point of view of semiconducting protections, since according these results it is possible to choose optimal materials and their layout for such a protection. As seen from the results the physical effects of electric field gradient correspond with measured results on a real sample substituting real machine stator.

\section{CONCLUSION}

The finite element method modelling has proved unambiguous relation between magnetic field strength and partial discharges in electric machinery. As show the results for each studied case of winding insulation anticorona protection the highest partial discharge activity appears in case of simple winding bar insulation, where a significant gradient of electric field appears.

The comparison of two cases of bar insulation with anti-corona protection also shows, that the amount of partial discharges may be affected by suitable choice of amount of anti-corona protective layers and also their suitable geometric layout. In studied cases the lowest 
amount of PD has been measured for four phase anticorona protection where the space dependency of electric field strength is nearly continuous curve without significant gradients of electric field.

Using developed methodology and available measuring stands it is possible to provide optimizations of anticorona protection, which have been mostly impossible yet. These optimizations will be a subject of further research at University of West Bohemia.

\section{Acknowledgement}

This work was supported by the research project GA102/09/1164 of Czech Science Foundation.

\section{REFERENCES}

[1] HUDON, C.-BELEC, M.: Partial Discharge Signal Interpretation for Generator Diagnostics, Dielectrics and Electrical Insulation, IEEE Transactions on 12 No. 2 (Apr 2005), 297-319.

[2] SUWARNo MIZUTANI, T.: Diagnosis of Insulation Conditions: Interpretation of Partial Discharges from $\varphi-q-n$ Pattern, Pulse-Sequence and Pulse Waveform, Condition Monitoring and Diagnosis, 2008. CMD 2008. International Conference on, 21-24 April 2008, pp. 60-63.

[3] SHUNYUAN LI-CHOW, J. M. Y.: Partial Discharge Measurements on Hydro Generator Stator Windings Case Studies, Electrical Insulation Magazine 23 No. 3 (May-June 2007), 5-15, IEEE.

[4] KLASna, J.-MARTineK, P.-FAntA, R.-PiHeRA, J. Partial Discharges In High-Voltage Insulation of Turbogenerators, Solid Dielectrics (ICSD), 2010 10th IEEE International Conference on, 4-9 July 2010, pp. 1-4.

[5] EMERY, F. T.: Reduction Techniques of Partial Discharge, Dissipation Factor, and External Corona for High Voltage Stator Windings, Electrical Insulation Conference, 2009. EIC 2009, IEEE, May 312009 - June 3 2009, pp. 315-327.

[6] SOLTANI, R.-DAVID, E.-LAMARRE, L. : Study on the Effect of Humidity on Dielectric Response and Partial Discharges Activity of Machine Insulation Materials, Electrical Insulation Conference, 2009. EIC 2009, IEEE, May 312009 - June 3 2009, pp. 343-347.

[7] GREG, C.-STONE, E. A.-BOULTER, I. : Electrical Insulation for Rotating Machines: Design, Evaluation, Aging, Testing, and Repair, IEEE Press Editorial Board, 23 AUG 2004.

[8] HUdON, C.-BELEC, M.-LEVESQUE, M.: Study of Slot Partial Discharges in Air-Cooled Generators, Dielectrics and Electrical Insulation, IEEE Transactions on 15 No. 6 (Dec 2008), $1675-1690$.

[9] STEIN, R.-LAIRD, T.-WATTERS, C. : Case Studies Using an Additional Neutral Point PD Sensor for Generator Stator Monitoring, Electrical Insulation, 2008. ISEI 2008. Conference Record of the 2008 IEEE International Symposium on, 9-12 June 2008, pp. 551-557.

[10] CHEN XIAOHUI-LIU DEJUN-MA ZHONGHUA: The High Accuracy Simulation of Resistivity LWD Electric Field Using Self-Adaptive hp-FEM, Measuring Technology and Mechatronics Automation (ICMTMA), 2010 International Conference on, vol. 3, 13-14 March 2010, pp. 874-877.

[11] SHARIFI, E.-JAYARAM, S. H.-CHERnEY, E. A.: Temperature and Electric Field Dependence of Stress Grading on Form-Wound Motor Coils, Dielectrics and Electrical Insulation, IEEE Transactions on $\mathbf{1 7}$ No. 1 (Feb 2010), 264-270.

[12] IEC 60270:2000/BS EN 60270:2001 "High-Voltage Test Techniques - Partial Discharge Measurements".
13] IEEE 1434-2000 "IEEE Trial-Use Guide to the Measurement of Partial Discharges in Rotating Machinery".

14] KASHIHA, M. A.-TOOTAGHAJ, D. Z.-DJAMShIDI, D.: Partial Discharge Source Classification and De-Noising in Rotating Machines using Discrete Wavelet Transform and Directional Coupling Capacitors, Transmission \& Distribution Conference \& Exposition: Asia and Pacific, 2009, 26-30 Oct 2009, pp. 1-4.

15] SOLTANI, R.-DAVID, E.-LAMARRE, L.: The Impact of Humidity on Partial Discharge Activity of Large Rotating Machines, Electrical Insulation (ISEI), Conference Record of the 2010 IEEE International Symposium on, 6-9 June 2010, pp. 1-6.

[16] SMeeton, P.-BOUsBaine, A.: Fault Diagnostic Testing using Partial Discharge Measurements on High Voltage Rotating Machines, Universities Power Engineering Conference (UPEC), 2009 Proceedings of the 44th International, 1-4 Sep 2009, pp. $1-5$.

[17] HEITZ, C. : Physical Modelling and Mathematical Description of PD Processes with Application to PRPD patterns, High Voltage Engineering, 1999. Eleventh International Symposium on (Conf. Publ. No. 467), vol. 5, 1999, pp. 356-361.

[18] BELEC, M.-HUDON, C.-GUDDEMI, C. : Laboratory Study of Slot Discharge Characteristic PRPD Patternsinbook Electrical Insulation Conference and Electrical Manufacturing \& Coil Winding Conference, 2001. Proceedings.

19] GROsS, D. W.-FRUTH, B. A.: Characteristics of Phase Resolved Partial Discharge Pattern in Spherical Voids, Electrical Insulation and Dielectric Phenomena, 1998. Annual Report. Conference on, vol. 2, 25-28 Oct 1998, pp. 412-415.

[20] HEITZ, C.: A General Stochastic Approach to Partial Discharge Processes, Conduction and Breakdown in Solid Dielectrics, 1998. ICSD '98. Proceedings of the 1998 IEEE 6th International Conference on, 22-25 June 1998, pp. 139-144.

[21] CONTIN, A.-Al-MARZOUQI, H. : Searching for Partial Discharge patterns for the Dentification of Defects of Insulation Systems in ac Rotating Machines, Electrical Insulation Conference, 2009. EIC 2009. IEEE, May 31 - June 3, 2009, pp. 405-408.

[22] KANEIWA, H.-MURAKAMI, N.-SAKAI, M.-INOUE, Y. : Detection of Partial Discharge from Stator Coil of Rotating Machine, Properties and Applications of Dielectric Materials, 2006. 8th International Conference on, June 2006, pp. 451-454.

23] HEE-SANG SHIN-JAE-CHUL KIM : A Study on Partial Discharge Signals and Noises at On-Line Generator Stator Windings, Transmission \& Distribution Conference \& Exposition: Asia and Pacific, 2009, 26-30 Oct 2009, pp. 1-4.

[24] STONE, G. C.-CAMPBELL, S. R.-SEDDING, H. G. : Characteristics of Noise and Interphasal PD Pulses in Operating Stator Windings, Electrical Insulation Conference (EIC), 2011, 5-8 June 2011, pp. 15-19.

Received 12 November 2011

Petr Mráz has received his master degree at 2010 at the University of West Bohemia. He is currently PhD student at Department Technologies and Measurements, division Electrotechnologies. His field of study is partial discharge activity in electric devices.

Vladimír Kindl has received $\mathrm{PhD}$ degree at the University of West Bohemia. He is currently the senior lecturer and researcher at the Department of Electromechanics and Power Electronics. He currently focuses on problems of electric machinery and its modelling using finite element method.

Karel Hruška has received PhD degree at the University of West Bohemia. Currently he works as junior researcher and senior lecturer at the Department of Electromechanics and Power Electronics and at Regional Innovation Centre for Electrical Engineering. His main areas of activities are design and analysis of electric machinery. 